\title{
IN VITRO SCREENING OF INDIGENOUS RHIZOBIUM ISOLATES OF ARACHIS HYPOGAEA FOR SPECIFIC PLANT GROWTH PROMOTING PHYSIOLOGICAL TRAITS
}

\author{
V. Nithyakalyani, J. Neenapriya \\ Assistant Professor, Department of Microbiology \\ Dr. MGR Janaki College of Arts and Science for Women
}

ABSTRACT - Plant growth promotion activity by PGPR is a classic example of plant microbe interaction. In vitro screening of Rhizobium isolates for specific physiological traits were analyzed as the plant growth substances production, PHB assay and antagonistic activity of the rhizobial isolates serves as a selection criterion of the effective strains. These characteristics are generally a prerequisite of good plant growth promoting bioinoculants. In the present investigation of 45 isolates for plant growth promotion, nine isolates (VRh9, KRh7, TRh11, VRh2, KRh11, TRh7, KRh3, VRh4 \& TRh2) exhibited increased production of the growth factors tested and antagonistic activity. Seventyfour percent (74\%) of the Rhizobium species tested produced IAA. When tested for EPS production, 36 $\mu \mathrm{g} / \mathrm{mL}$ was observed in Rhizobium TRh11 followed by $32 \mu \mathrm{g} / \mathrm{mL}$ in KRh11 \& VRh9 respectively. Twenty-seven (27) isolates of 45 strains tested produced an orange halo zone in Chromazurol $S$ agar indicating Siderophore production. When tested for HCN production, $60 \%$ of the isolates produced HCN and ammonia production was detected in 35 isolates (75\%). Qualitative screening for PHB production indicated that all the 45 isolates demonstrated positive results, and the isolates VRh9, KRh7, TRh11, VRh2, KRh11, TRh7, KRh3, VRh4 \& TRh2 displayed maximum absorption. All isolates proficiently fixed nitrogen with substantial variation among the isolate Rhizobium TRh11 which fixed higher nitrogen content. The selected nine Rhizobium strains were scrutinized for their antagonistic activity against two isolates of pathogenic fungal strains (Aspergillus niger and Fusarium oxysporum). Rhizobium species TRh11 and VRh2 explicited commendative prohibitive activity which notably truncated the growth of the fungal isolates tested.

Keywords: PGPR, Siderophore, IAA, Nitrogen fixation, HCN, PHB, Rhizobium, Groundnut

\section{INTRODUCTION}

The use of PGPR constituting a small portion of the rhizobacterial community, is an environmentally sound way of increasing crop yields which profoundly activates plant growth through mechanisms of phosphate solubilization, biological nitrogen fixation, improvement of nutrient uptake, and phytohormone production. Through production of antibiotic, hydrolytic enzymes, Hydrogen Cyanide and Siderophores, biological control of plant pathogens and deleterious microbes could be achieved which improve plant health and growth ${ }^{1 \& 2}$.

Indole Acetic Acid (IAA), a common plant growth promoting hormone helps in fixation of nitrogen at a percentage of $96 \%$ and PGPR community could directly enhance plant growth by IAA, cytokinin production, increase nutrient uptake and promote early seedling root ${ }^{3}$. PGPR produced Hydrogen Cyanide to control growth of different types of pathogens. Available literature revealed that rhizobia also produced Hydrogen Cyanide (HCN). Rhizobium species produce variety of exo-polysaccharide (EPS) possessing high moisture holding capacity with iron chelation property serves to maintain moisture in their immediate environment to protect the organism from desiccation and supplies essential energy under nutrient deficit state 4 . The commercialization of microbial EPS for delivery of plant growth regulators and pesticides through encapsulation technology has possible future outcomes. Siderophores production for increasing the uptake of iron by the roots is a profound character of rhizospheric community ${ }^{5}$. Stimulation of 


\section{International Journal of Engineering Applied Sciences and Technology, 2020 \\ Vol. 5, Issue 6, ISSN No. 2455-2143, Pages 274-287 \\ Published Online October 2020 in IJEAST (http://www.ijeast.com)}

legume Rhizobium interaction depends on phytohormones which stimulates root growth to provide sites for rhizobial infection for nodulation. Legume nodulation promotion through flavonoid molecules or flavonoid signal molecules has been extensively studied ${ }^{6}$.

Rhizobium sequester the carbon components provided by the legumes which is stored as Poly-3Hydroxybutryate (PHB) granules which benefit the host plants during respiration mechanisms and protects nitrogenase enzyme from oxygen inactivation during the development of seed ${ }^{7}$. PHB can enhance the stress tolerance of rhizobia and help in their own fitness ${ }^{8}$. Many reports indicate the biocontrol ability of rhizobial strain through production of antibiotics and cell wall degrading enzymes ${ }^{9}$. Usage of such strains against soil borne fungi which cause diseases of groundnut can lead to potential control.

One of the major issues in efficient bio fertilizer production using Rhizobium species is the quest for strains possessing the unique properties of plant growth induction and defense pathways. The present study discusses the methods used to search an effective strain of Rhizobium species capable of producing IAA, Siderophore, Ammonia, Hydrogen Cyanide and the ability to fix increased levels of nitrogen. The strains were also screened for their potential to act as a biocontrol agent and production of PHB granules. The strains identified as Rhizobium species through morphological and biochemical studies were analyzed for growth factor promotion factors.

\section{MATERIALS AND METHODS}

Root nodules of Arachis hypogaea plants collected from three different geographical locations of Tamil Nadu were screened for the distribution of Rhizobium species. A total of 45 TRh1-TRh15 (Total: 15 strains), KRh1-KRh16 (Total: 16 strains) and VRh1-VRh14 (Total: 14 strains) isolates of Rhizobium were then characterized based on their PGPR properties.

\subsection{Indole Acetic Acid Production}

The IAA production by Rhizobium cultures were detected by colorimetric quantification ${ }^{10}$. Cultures were grown in $25 \mathrm{~mL}$ Luria-Bertani broth amended with $50 \mu \mathrm{g} / \mathrm{mL}$ tryptophan, followed by incubation at $28 \pm 2{ }^{\circ} \mathrm{C}$ for 48 hours. The cultures were then centrifuged at $10,000 \mathrm{rpm}$ for 15 minutes. Three $\mathrm{mL}$ of supernatant was taken for each culture and 2-3 drops of O-phosphoric acid was added. Then $4 \mathrm{~mL}$ of Salkowski reagent $\left(1 \mathrm{~mL}\right.$ of $0.5 \mathrm{M} \mathrm{FeCl}_{3}$ in 50 $\mathrm{mL}$ of $35 \% \mathrm{HClO}_{4}$ ) was added to each aliquot. The samples were then incubated for 25 minutes at room temperature and the absorbance was read at $530 \mathrm{~nm}$. The obtained auxin quantification values were recorded by preparing calibration curve made using IAA as standard $(10-100 \mu \mathrm{g} / \mathrm{mL})$ and the results were recorded as + or - respectively for production or absence of IAA production and the IAA concentration deduced using the IAA calibration curve with standard IAA solutions. IAA standard stock solution was prepared in $50 \%$ ethanol at $100 \mu \mathrm{g} / \mathrm{mL}$ of IAA. Different standard IAA concentrations were prepared as aqueous solution of IAA ranging from $10 \mu \mathrm{g}$ to $100 \mu \mathrm{g}$. To each $1 \mathrm{~mL}$ of the standard, $2 \mathrm{~mL}$ of Salkowski reagent was added. Readings were taken after 25 minutes' incubation at $530 \mathrm{~nm}$ by UVspectrophotometer. Standard graph was prepared by plotting concentration of IAA in micrograms $/ \mathrm{mL}$ Vs optical density at $530 \mathrm{~nm}$.

\subsection{Screening the isolates for production of EPS ${ }^{11}$}

Rhizobium sp. isolates were screened for EPS production by growing it on CRYEMA at $28^{\circ} \mathrm{C}$ for 48 hours and observed for the formation of gummy/mucoid colonies of Rhizobium. EPS production in liquid media was carried out by separately growing the $6 \times 10^{-6}$ cells $\mathrm{mL}^{-1}$ of Rhizobium in YEM Broth (M1824, HiMedia, India) at $28^{\circ} \mathrm{C}$ for 8-10 days with constant shaking at $120 \mathrm{rpm}$. Following the incubation, inoculated flasks were observed for change in the rheology. Increase in the viscosity of broth was taken as an indicator of EPS production. After incubation, culture broth was centrifuged at $3500 \mathrm{rpm}$ for 30 minutes. One $\mathrm{mL}$ of supernatant was mixed with two volumes of chilled acetone. The crude polysaccharide developed was collected by centrifugation at $3500 \mathrm{rpm}$ for 30 minutes. The EPS was washed with distilled water and acetone alternately and transferred into a filter paper and weighed after drying overnight at room temperature. Results were tabulated according to the weight measured after overnight incubation and expressed as $\mu \mathrm{g} / \mathrm{mL}$.

\subsection{Siderophore Production ${ }^{12}$}

Siderophore (iron chelator) production of the isolates were determined using Chromazurol S (CAS) method developed by Schwyn and Neilands, 1987. The media with dye was poured into Petri plates and the Rhizobium isolates were streaked onto the plates and incubated for six days at $28 \pm 2^{\circ} \mathrm{C}$. Formation of an orange halo zone indicated the Siderophore (ironchelator) production and they were grouped based on diameter of the halo, i.e., $10 \mathrm{~mm}$ as strong reaction $(++)$, moderate growth $(+)$ and no zone formation (-). 


\section{International Journal of Engineering Applied Sciences and Technology, 2020 Vol. 5, Issue 6, ISSN No. 2455-2143, Pages 274-287 \\ Published Online October 2020 in IJEAST (http://www.ijeast.com)}

\subsection{Hydrogen cyanide production ${ }^{13}$}

Nutrient agar (M001, HiMedia, India) was modified by supplementing with $4.4 \mathrm{~g} / 1$ of glycine and the isolates were streaked on modified agar plates. A Whatman No.1 filter paper soaked in $2 \%$ sodium carbonate in $0.5 \%$ picric acid solution was placed at the top of the plate. After sealing the plates with Para film, incubation at $36 \pm 2{ }^{\circ} \mathrm{C}$ for four days followed by development of orange to red color confirms Hydrogen Cyanide (HCN) production (Lorck, 1948).

\subsection{Nitrogen fixing efficacy: Estimation of total nitrogen fixed by Micro-Kjeldahl method}

Micro-Kjeldahl's method was used for estimating the nitrogen fixing efficacy of rhizobial isolates. The rhizobial cultures grown in $10 \mathrm{~mL}$ of YEM Broth were incubated for 48 hours in a rotary shaker at room temperature. Cell concentrations were determined at $10^{5} \mathrm{cfu} / \mathrm{mL}$ of each isolate by plate counts on YEM Agar ${ }^{14}$. The uninoculated media serves as control. The concentration of nitrogen fixed was then evaluated and estimated by Kjeldahl method.

\subsubsection{Sample preparation, Distillation, Digestion process and Titration}

After incubation period, the media containing isolates were digested by adding the salt mixture, transferred to boiling tubes and a $0.5 \mathrm{~g}$ selenium mixture catalyst (50:10:1 ratio of Potassium Sulphate, Copper Sulphate and metallic selenium) added followed by $3.5 \mathrm{~mL}$ of concentrated sulphuric acid to initiate the digestion process. The set-up was left in digestion chamber for two hours. The digested samples after retrieving from the chamber in a time period of two hours, were allowed to cool for 30 minutes, transferred to distillation flask and $40 \mathrm{~mL}$ of $10 \mathrm{~N} \mathrm{NaOH}$ were added to proceed with the distillation process. $\mathrm{NH}_{3}$ released was collected into $20 \mathrm{~mL}$ of $1 \%$ Boric acid and titration done against $0.01 \mathrm{M} \mathrm{HCl}$. The quantities of nitrogen reported represent the average of duplicate cultures after deducting the average of duplicate cultures ${ }^{15}$. The total nitrogen percentage was calculated by the following formula:

$$
\text { Percentage of nitrogen in the sample }=
$$

(sample titre - blank titre) $x 1.4007 x$ Normality of HClx 100

\section{Weight of the sample $x 1000$}

\subsection{Ammonia Production}

The rhizobial isolates were tested for the production of ammonia in peptone water following the method of Cappuccino \& Sherman ${ }^{16}$, 1996. Nessler's reagent was added to fresh cultures of the isolates grown in peptone water for 48 hours at room temperature. Development of brown to yellow color indicates positivity for ammonia production.

\subsection{Qualitative and Quantitative Screening for the production of PHB using Sudan Black Staining Technique}

The rhizobial strains obtained from root nodules of groundnut plant were screened for the PHB production by viable colony staining technique. The cultures were grown on Minimal Salt Medium (M1253, HiMedia, India) supplemented with glucose $(2 \%)$ as a sole carbon source and incubated at $30^{\circ} \mathrm{C}$ for 48 hours. The plates were flooded with Sudan black stain after incubation to detect the secretion of intracellular lipid granules. The qualitative screening method of PHB production of the isolates based on Sudan black absorption pattern by the rhizobial strains on the agar plates were characterized as Maximum, Moderate and Minimum ${ }^{17}$.

\subsubsection{Extraction of Poly- $\beta$-hydroxybutyrate granules}

The Rhizobium strains which showed maximum production of PHB based on qualitative screening methods of $\mathrm{PHB}$ production were subjected to quantification of PHB by centrifuging the bacterial cells containing the polymer at $10,000 \mathrm{rpm}$ for 10 minutes and the pellet was resuspended into alkaline sodium hypochlorite solution $(5.25 \%-5.5 \%)$ which is maintained at a $\mathrm{pH}$ of $10.0-10.5$. The suspension was incubated at room temperature for one hour and centrifugation was carried out again at $10,000 \mathrm{rpm}$ for 10 minutes followed by discarding the supernatant. Using water, alcohol and acetone, the cell pellet containing PHB was washed. The extracted polymer was dried for two hours at $105^{\circ} \mathrm{C}$ and weighed. Dry weight of extracted polymer was expressed as $\mathrm{g} / \mathrm{L}$. The results indicate that a relationship might exist between dry cell weight and dry weight of PHB. Residual biomass was estimated as the difference between dry cell weight and dry weight of $\mathrm{PHB}^{17} \& 18$.

\subsubsection{Estimation of Dry Cell Weight (DCW)}

The MSM medium with rhizobial growth was collected and centrifuged at 10,000 rpm for 15 minutes after incubation at $37^{\circ} \mathrm{C}$ for 48 hours. Supernatant was discarded and the cell pellet was washed twice in deionized water and recovered ${ }^{19} \& 20$. The cell pellet was dried for 24 hours at $100^{\circ} \mathrm{C}$ and the total bacterial cell dry weight was determined as $\mathrm{g} / \mathrm{L}$.

\subsubsection{Estimation of $P H B$ from the selected isolates Intracellular PHB accumulated is estimated using the following formula and expressed as}




\section{International Journal of Engineering Applied Sciences and Technology, 2020 \\ Vol. 5, Issue 6, ISSN No. 2455-2143, Pages 274-287 \\ Published Online October 2020 in IJEAST (http://www.ijeast.com)}

percentage:

\section{PHB accumulation (\%)=Dry Weight of extracted $\operatorname{PHB}(\mathrm{g} / \mathrm{L}) \times 100 / \mathrm{DCW}(\mathrm{g} / \mathrm{l})$}

\subsection{Antagonistic activity of Rhizobium against} fungal pathogens

The antifungal effect of nine (VRh9, KRh7, TRh11, VRh2, KRh11, TRh7, KRh3, VRh4 \& TRh2) rhizobial isolates selected based on the preliminary screening methods of production of cell wall degrading enzymes and identification properties of potential PGPR traits against pathogenic fungi (Aspergillus niger and Fusarium oxysporum) was estimated by well diffusion method developed by Arfaoui method ${ }^{21}$. In vitro antagonistic activity was performed on Potato Dextrose Agar (PDA- M096, HiMedia, India) in Petri plates by using dual culture technique. Isolates of Rhizobium sp. were streaked across the two edges of the plates and a disc of fungal growth of Fusarium oxysporum and Aspergillus niger cut from the edge of a seven day old cultures were placed in the center of the plates. Ampicillin antibiotic was used as a positive control and saline as negative control. The plates were incubated for seven days at $28^{\circ} \mathrm{C}$ for antifungal activity and the percent growth inhibition was recorded using the formula,

$$
\% \text { inhibition }=(R-r) / R \times 100
$$

where, $R$-Radius of the fungal colony opposite to the antagonist

$r$-Radius of the fungal colony towards the antagonist

\section{RESULTS}

Plant growth promotion activity by PGPR is a classic example of plant microbe interaction. In the forthcoming section, the plant growth substances production, PHB assay and antagonistic activity of the rhizobial isolates were discussed which serves as selection criterion of the effective strains. These characteristics are generally a prerequisite of good plant growth promoting bio-inoculant.

\subsection{IAA production}

In the present study, it was observed that the maximum production of IAA was observed in nine isolates (VRh9, KRh7, TRh11, VRh2, KRh11, TRh7, $\mathrm{KRh} 3, \mathrm{VRh} 4$ \& TRh2). The isolated strains and MTCC strain synthesized IAA in the presence of tryptophan.

In IAA production, the amount of IAA produced by the promising isolates were: TRh2: 96 ( $\mu \mathrm{g} / \mathrm{mL})$, TRh7: $97.5(\mu \mathrm{g} / \mathrm{mL})$, TRh11: $95.5(\mu \mathrm{g} / \mathrm{mL})$,
KRh3: $94.5(\mu \mathrm{g} / \mathrm{mL}), \mathrm{KRh} 7: 92.5(\mu \mathrm{g} / \mathrm{mL}), \mathrm{KRh} 11$ : 95.5 $(\mu \mathrm{g} / \mathrm{mL}), \quad$ VRh2: $92.5(\mu \mathrm{g} / \mathrm{mL})$, VRh4: 96 $(\mu \mathrm{g} / \mathrm{mL})$, VRh9: $95(\mu \mathrm{g} / \mathrm{mL})$ and MTCC: 72.5 $(\mu \mathrm{g} / \mathrm{mL})$ respectively (Table 1$)$. Among the 45 isolates, nine strains produced higher concentrations of IAA above the levels elaborated by the reference strain. The distribution of IAA production in comparison with the reference strain (control strain MTCC), which elaborated an IAA amount of 72.5 $\mu \mathrm{g} / \mathrm{mL}$, the rhizobial isolates of Tiruvallur district, showed high production of IAA. Similar results were observed in few rhizobial isolates of Kanchipuram and Vellore which produced increased amounts of IAA. It is evident from the results, the dependency of IAA production on the availability of tryptophan which proves the fact of adaptability of tryptophan dependent pathway by microbes. The isolates in the current study varied in their intrinsic ability to produce IAA as the production varied under the same condition.

\subsection{Exo-Polysaccharide (EPS) production}

Formation of mucoid gummy colonies on YEMA and increase in the viscosity of YEMB indicated the ability of Rhizobium sp. to produce EPS. Totally nine strains along with MTCC produced maximum EPS after 72 hours of incubation. VRh9, KRh7, TRh11, VRh2, KRh11, TRh7, KRh3, VRh4 \& $\mathrm{TRh} 2$ isolates produced EPS at higher levels when compared to other strains.

A maximum EPS production of $36 \mu \mathrm{g} / \mathrm{mL}$ was observed in TRh11 followed by $32 \mu \mathrm{g} / \mathrm{mL}$ in KRh11 \& VRh9 respectively, whereas, MTCC (45 $\mu \mathrm{g} / \mathrm{mL}$ ) has produced the high amount of EPS. Figures $1.1,1.2 \& 1.3$ indicates the EPS production results of the rhizobial isolates in comparison with the reference strain indicated by the diagonal cutoff. Among the Tiruvallur isolates, TRh2, TRh7 and TRh11 secreted $28 \mu \mathrm{g} / \mathrm{mL}, 31 \mu \mathrm{g} / \mathrm{mL}$ and $36 \mu \mathrm{g} / \mathrm{mL}$ respectively. Kanchipuram isolates KRh3, KRh7 and KRh11 elaborated $29 \mu \mathrm{g} / \mathrm{mL}, 28 \mu \mathrm{g} / \mathrm{mL}$ and $32 \mu \mathrm{g} / \mathrm{mL}$ distinctively. Vellore isolates VRh2, VRh4 and VRh9 at disparate levels, produced $26 \mu \mathrm{g} / \mathrm{mL}, 30 \mu \mathrm{g} / \mathrm{mL}$ and $32 \mu \mathrm{g} / \mathrm{mL}$ of EPS respectively. Even though the figures indicate that EPS production was high in Rhizobium leguminosarum MTCC 99, isolated native strains also produced equivalent amount of EPS. High amount of EPS production was mostly by the fast growing strains and lowest amount produced by the slow growing strains. Intermediate values were obtained with few fast and slow growing strains in the present study.

\subsection{Siderophore production}

Another interesting trait of Rhizobium is the ability to secrete siderophores (ferric-specific ligands) 
which chelates ions and other metals contributing to disease suppression and acquisition of ferrous to plants for increasing the crop growth. Amongst the overall isolates (45), only nine (VRh9, KRh7, TRh11, VRh2, $\mathrm{KRh} 11, \mathrm{TRh} 7, \mathrm{KRh} 3, \mathrm{VRh} 4 \& \mathrm{TRh} 2)$ isolates along with MTCC were able to produce maximum siderophores (good growth: ++ ) (which were indicated by moderate yellow-orange halo around their colonies due to removing the color from CAS dye-Fe IIIcomplex) and low Siderophore (expressed as a weak zone) (Table 2). Few isolates depicted negative results for Siderophore production (TRh1, TRh4, TRh6, TRh10, TRh12, TRh15, KRh2, KRh5, KRh6, KRh8, KRh9, KRh13, KRh14, VRh5, VRh6, VRh7, VRh13 and VRh14). The district wise percentage production of the isolates was $64 \%>60 \%>54 \%$ of Vellore, Tiruvallur and Kanchipuram respectively.

Table 1: IAA production of the isolated strains of Rhizobium from Arachis hypogaea

\begin{tabular}{|c|c|c|c|c|c|}
\hline Isolates & $\begin{array}{c}\text { IAA } \\
\text { productio } \\
\mathbf{n} \\
(\mu \mathrm{g} / \mathrm{mL}) \\
\end{array}$ & Isolates & $\begin{array}{c}\text { IAA } \\
\text { producti } \\
\text { on } \\
(\mu \mathrm{g} / \mathrm{mL})\end{array}$ & $\begin{array}{c}\text { Isolate } \\
\quad \mathbf{s}\end{array}$ & $\begin{array}{c}\text { IAA } \\
\text { producti } \\
\text { on } \\
(\mu \mathrm{g} / \mathrm{mL})\end{array}$ \\
\hline TRh1 & 21.5 & KRh1 & 81 & VRh1 & 70 \\
\hline TRh2 & 96 & KRh2 & 80.5 & VRh2 & 92.5 \\
\hline TRh3 & 22 & KRh3 & 94.5 & VRh3 & 30 \\
\hline TRh4 & 17 & KRh4 & 87.5 & VRh4 & 96 \\
\hline TRh5 & 80.5 & KRh5 & 74 & VRh5 & 25 \\
\hline TRh6 & 66.5 & KRh6 & 68 & VRh6 & 45.5 \\
\hline TRh7 & 97.5 & KRh7 & 92.5 & VRh7 & 80 \\
\hline TRh8 & 66.5 & KRh8 & 46.5 & VRh8 & 24 \\
\hline TRh9 & 95.5 & KRh9 & 25 & VRh9 & 95 \\
\hline TRh10 & 16.5 & KRh10 & 38 & VRh10 & 18 \\
\hline TRh11 & 95.5 & KRh11 & 95.5 & VRh11 & 67 \\
\hline TRh12 & 18 & KRh12 & 55 & VRh12 & 52 \\
\hline TRh13 & 87.5 & KRh13 & 68 & VRh13 & 48 \\
\hline TRh14 & 20.0 & KRh14 & 70 & VRh14 & 40 \\
\hline \multirow[t]{2}{*}{ TRh15 } & 15.5 & KRh15 & 75 & & \\
\hline & & KRh16 & 40 & & \\
\hline $\begin{array}{c}\text { Rhizobium } \\
\text { leguminos } \\
\text { arum } \\
\text { MTCC } 99\end{array}$ & 72.5 & & & & \\
\hline
\end{tabular}

Table 2: Siderophore production of the rhizobial isolates

\begin{tabular}{|c|c|c|c|c|c|}
\hline Isolates & $\begin{array}{c}\text { Siderop } \\
\text { hore }\end{array}$ & Isolates & $\begin{array}{c}\text { Sideropho } \\
\text { re }\end{array}$ & $\begin{array}{c}\text { Isolate } \\
\text { s }\end{array}$ & $\begin{array}{c}\text { Siderop } \\
\text { hore }\end{array}$ \\
\hline TRh1 & - & KRh1 & + & VRh1 & + \\
\hline TRh2 & ++ & KRh2 & - & VRh2 & ++ \\
\hline TRh3 & + & KRh3 & ++ & VRh3 & + \\
\hline TRh4 & - & KRh4 & + & VRh4 & ++ \\
\hline TRh5 & + & KRh5 & - & VRh5 & - \\
\hline TRh6 & - & KRh6 & - & VRh6 & - \\
\hline TRh7 & ++ & KRh7 & ++ & VRh7 & - \\
\hline TRh8 & + & KRh8 & - & VRh8 & + \\
\hline TRh9 & + & KRh9 & - & VRh9 & ++ \\
\hline TRh10 & - & KRh10 & + & VRh10 & + \\
\hline TRh11 & ++ & KRh11 & ++ & VRh11 & + \\
\hline TRh12 & - & KRh12 & + & VRh12 & + \\
\hline TRh13 & + & KRh13 & - & VRh13 & - \\
\hline TRh14 & + & KRh14 & - & VRh14 & - \\
\hline TRh15 & - & KRh15 & + & & \\
\hline $\begin{array}{c}\text { Rhizobium } \\
\text { leguminosa } \\
\text { rum } \\
\text { MTCC 99 }\end{array}$ & ++ & KRh16 & + & & \\
\hline $\begin{array}{c}\text { Total } \\
\text { Positives }\end{array}$ & $\mathbf{9 ( 6 0 \% )}$ & + & $\mathbf{9 6 \% )}$ & & \\
\hline +R Rh1zbial & & & & \\
\hline ++ & + & & & \\
\hline
\end{tabular}

TRh- Rhizobial strain isolated from Tiruvallur;

KRh-Rhizobial strain isolated from Kanchipuram;

VRh-Rhizobial strain isolated from Vellore

Figure 1.1: EPS production $(\mu \mathrm{g} / \mathrm{mL})$ by Rhizobium isolates from Arachis hypogaea of Tiruvallur district (TRh1-TRh15)

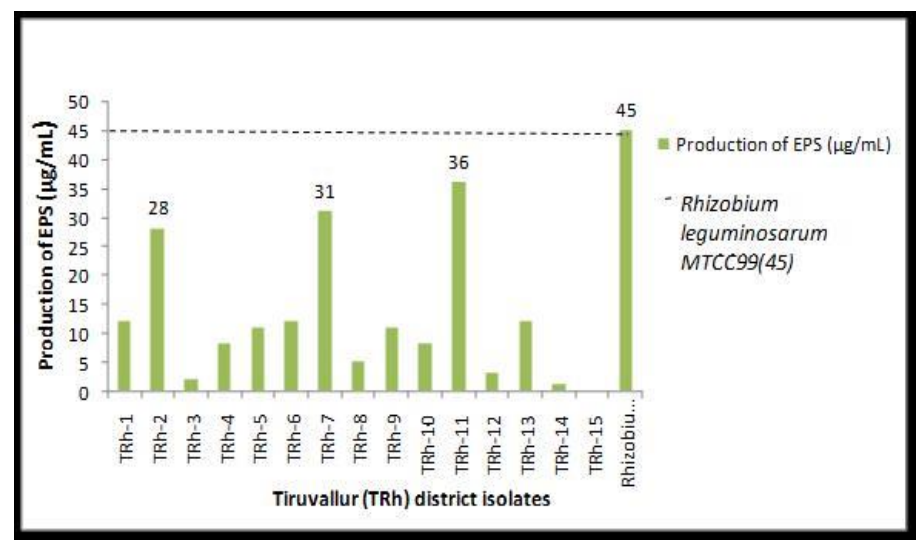

Figure 1.2: EPS production $(\mu \mathrm{g} / \mathrm{mL})$ by $R$ hizobium isolates from Arachis hypogaea of Kanchipuram district (KRh1-KRh16) 


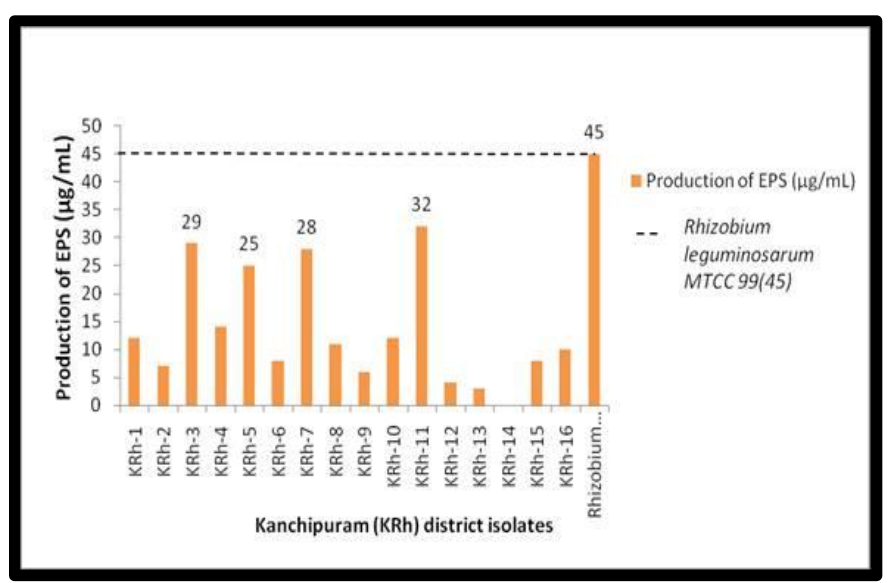

Figure 1.3: EPS production $(\mu \mathrm{g} / \mathrm{mL})$ by Rhizobium isolates from Arachis hypogaea of Vellore district (VRh1-VRh14)

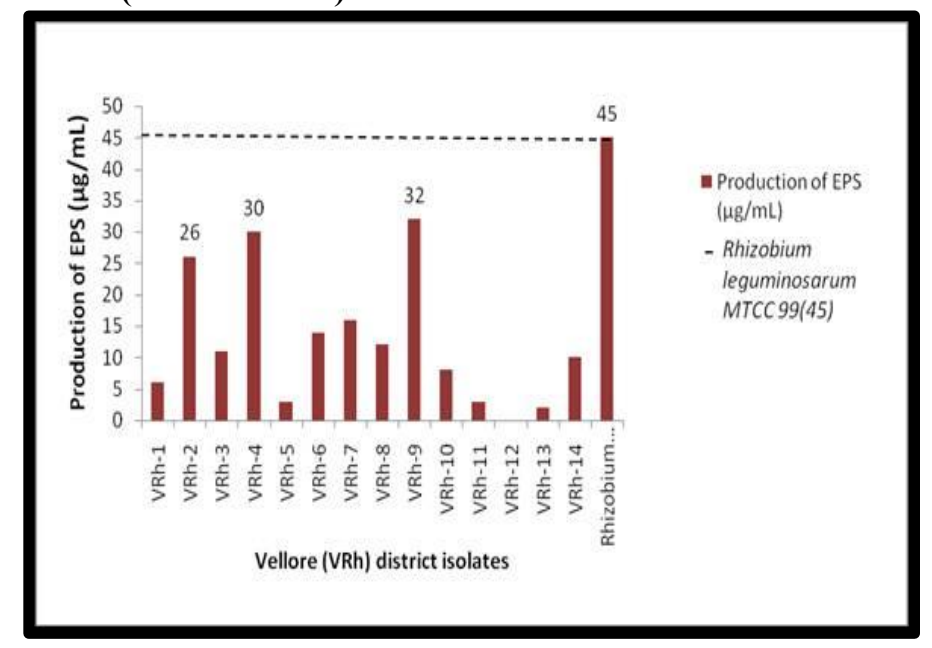

\subsection{Hydrogen Cyanide production}

Hydrogen Cyanide production was detected in twenty-seven rhizobial isolates and the data indicates maximum production by Tiruvallur isolates (80\%) followed by Kanchipuram (56\%) and Vellore districts (43\%). Out of 45 Rhizobium isolates, maximum Hydrogen Cyanide production was observed in nine strains (VRh9, KRh7, TRh11, VRh2, $\mathrm{KRh} 11, \mathrm{TRh} 7, \mathrm{KRh} 3, \mathrm{VRh} 4 \& \mathrm{TRh} 2)$ indicated as ++ along with MTCC (Table 3). Seventeen strains of Rhizobium isolates (TRh1, TRh3, TRh5, TRh6, TRh8, TRh9, TRh10, TRh12, KRh4, KRh8, KRh10, KRh12, KRh14, KRh15, VRh5, VRh10 and VRh11) elaborated low cyanide production revealed as a weak orange red pigmentation $(+)$, Whereas no Hydrogen Cyanide production (-) was observed in strains TRh13, TRh14, TRh15, KRh1, KRh2, KRh5, KRh6, KRh9, KRh13, KRh16, VRh1, VRh3, VRh6, VRh7, VRh8,
VRh12, VRh13 and VRh14.

Table 3: Hydrogen Cyanide production by Rhizobium isolates from Arachis hypogaea

\begin{tabular}{|c|c|c|c|c|c|}
\hline Isolates & HCN & Isolates & HCN & Isolates & HCN \\
\hline TRh1 & + & KRh1 & - & VRh1 & - \\
\hline TRh2 & ++ & KRh2 & - & VRh2 & ++ \\
\hline TRh3 & + & KRh3 & ++ & VRh3 & - \\
\hline TRh4 & + & KRh4 & + & VRh4 & ++ \\
\hline TRh5 & + & KRh5 & - & VRh5 & + \\
\hline TRh6 & + & KRh6 & - & VRh6 & - \\
\hline TRh7 & ++ & KRh7 & ++ & VRh7 & - \\
\hline TRh8 & + & KRh8 & + & VRh8 & - \\
\hline TRh9 & + & KRh9 & - & VRh9 & ++ \\
\hline TRh10 & + & KRh10 & + & VRh10 & + \\
\hline TRh11 & ++ & KRh11 & ++ & VRh11 & + \\
\hline TRh12 & + & KRh12 & + & VRh12 & - \\
\hline TRh13 & - & KRh13 & - & VRh13 & - \\
\hline TRh14 & - & KRh14 & + & VRh14 & - \\
\hline TRh15 & - & KRh15 & + & & \\
\hline $\begin{array}{c}\text { Rhizobium } \\
\text { leguminos } \\
\text { arum } \\
\text { MTCC 99 }\end{array}$ & ++ & KRh16 & - & & \\
\hline $\begin{array}{c}\text { Total } \\
\text { Positives }\end{array}$ & $12(80 \%)$ & & & & \\
\hline
\end{tabular}

\subsection{Nitrogen Fixation Assay}

The varied nitrogen fixation capacity of the rhizobial isolates obtained from root nodules has showed proven ability of nitrogen fixing capacity of the isolates. Nitrogen fixing ability, being the prominent characteristic of host rhizobial cells was well established with the results obtained as all the strains fixed nitrogen. It was observed that the maximum total nitrogen fixed by only nine isolates (VRh9, KRh7, TRh11, VRh2, KRh11, TRh7, KRh3, $\mathrm{VRh} 4 \& \mathrm{TRh} 2$ ) and remaining isolates fixed minimum nitrogen level in comparison with the reference strain (Figure 2.1, 2.2 and 2.3). Out of the 45 isolates, TRh11 and $\mathrm{VRh} 2$ fixed nitrogen at a rate of $0.52 \%$ and $0.53 \%$ on par with Rhizobium leguminosarum MTCC 99 strain $(0.54 \%)$.

Figure 2.1: Amount of nitrogen fixed (\%) by the Rhizobium isolates from Arachis hypogaea of Tiruvallur district (TRh1-TRh15) 


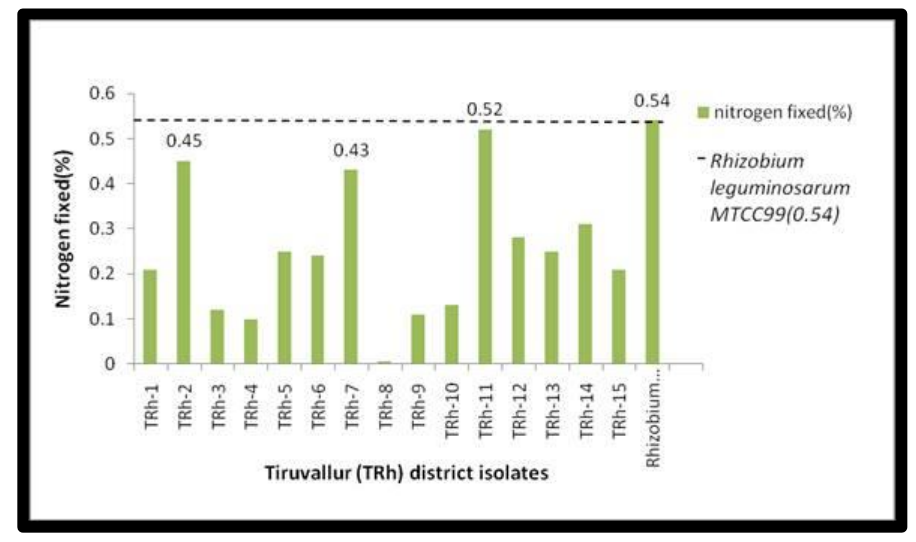

Figure 2.2: Amount of nitrogen fixed (\%) by the Rhizobium isolates from Arachis hypogaea of Kanchipuram district (KRh1-KRh16)

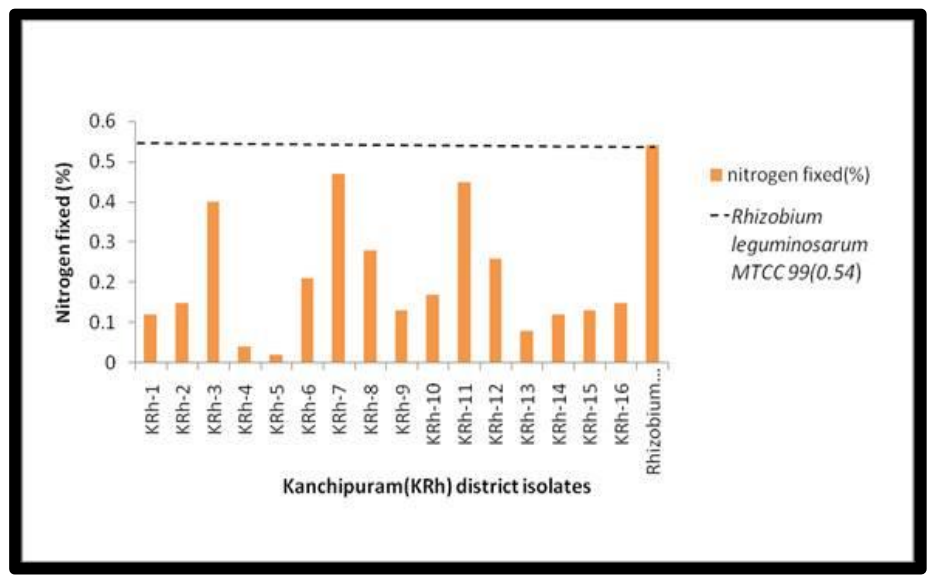

Figure 2.3: Amount of nitrogen fixed (\%) by the Rhizobium isolates from Arachis hypogaea of Vellore district (VRh1-VRh14)

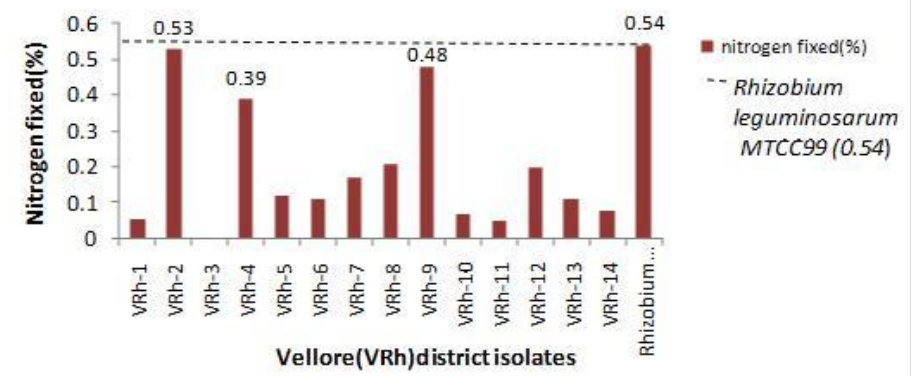

\subsection{Ammonia Production}

The rhizobial isolates were screened for the production of ammonia, an important trait of PGPR which indirectly influences the plant growth and the data unveiled authenticates the ammonia production ability of majority of the isolates. Out of the 45 strains tested, $35(75 \%)$ were positive for ammonia production. The district wise data of rhizobial isolates positive for ammonia production is presented in figure 3 reveals that Tiruvallur strain showed 93\% followed by Vellore (71\%) and Kanchipuram (69\%).

Figure 3: Percentage of Rhizobium isolates from Arachis hypogaea positive for ammonia production

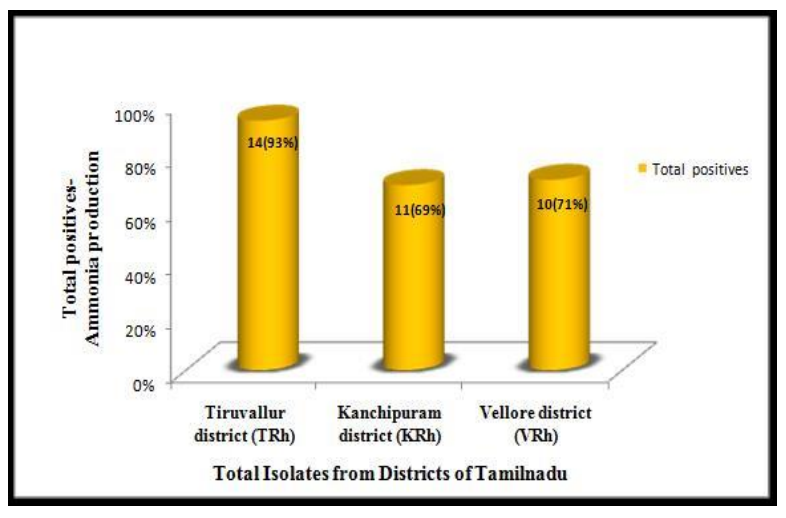

\subsection{PHB production}

\subsubsection{Qualitative screening for PHB producing rhizobial isolates}

To reveal the production of PHB through Sudan black absorption, growth pattern of isolates by viable colony staining technique was performed and the results were tabulated. Out of 45 Rhizobium isolates, nine isolates showed strong Sudan black absorption $(+++)$ PHB. Further, six isolates scored moderate absorption $(++)$ and 27 isolates displayed less absorption of Sudan black $(+)$. Rhizobial isolate KRh13 failed to absorb Sudan black which is indicative of absence of PHB production (Table 4). Based on the qualitative results, the efficient PHB producing strains were tested for quantitative methods of production of PHB granules.

\subsubsection{Extraction and Quantification of PHB}

Table 5 elaborates the yield of PHB in efficient Rhizobium strains (VRh9, KRh7, TRh11, VRh2, KRh11, TRh7, KRh3, VRh4 \& TRh2) selected based on the qualitative screening for PHB production. Extracted PHB concentration and percentage yield of PHB was observed on a higher scale for TRh11 and $\mathrm{VRh} 2$ isolates as it yielded $30.01 \%$ and $29.88 \%$ respectively when compared with MTCC strain (Figure $4 \& 5$ ). The results indicate that a significant relationship might exist between the dry cell weight and $\mathrm{PHB}$ production. 
Table 4: Qualitative screening for PHB producing Rhizobium isolates from Arachis hypogaea
Figure 5: Yield \% of PHB produced by the selected Rhizobium isolates of Arachis hypogaea

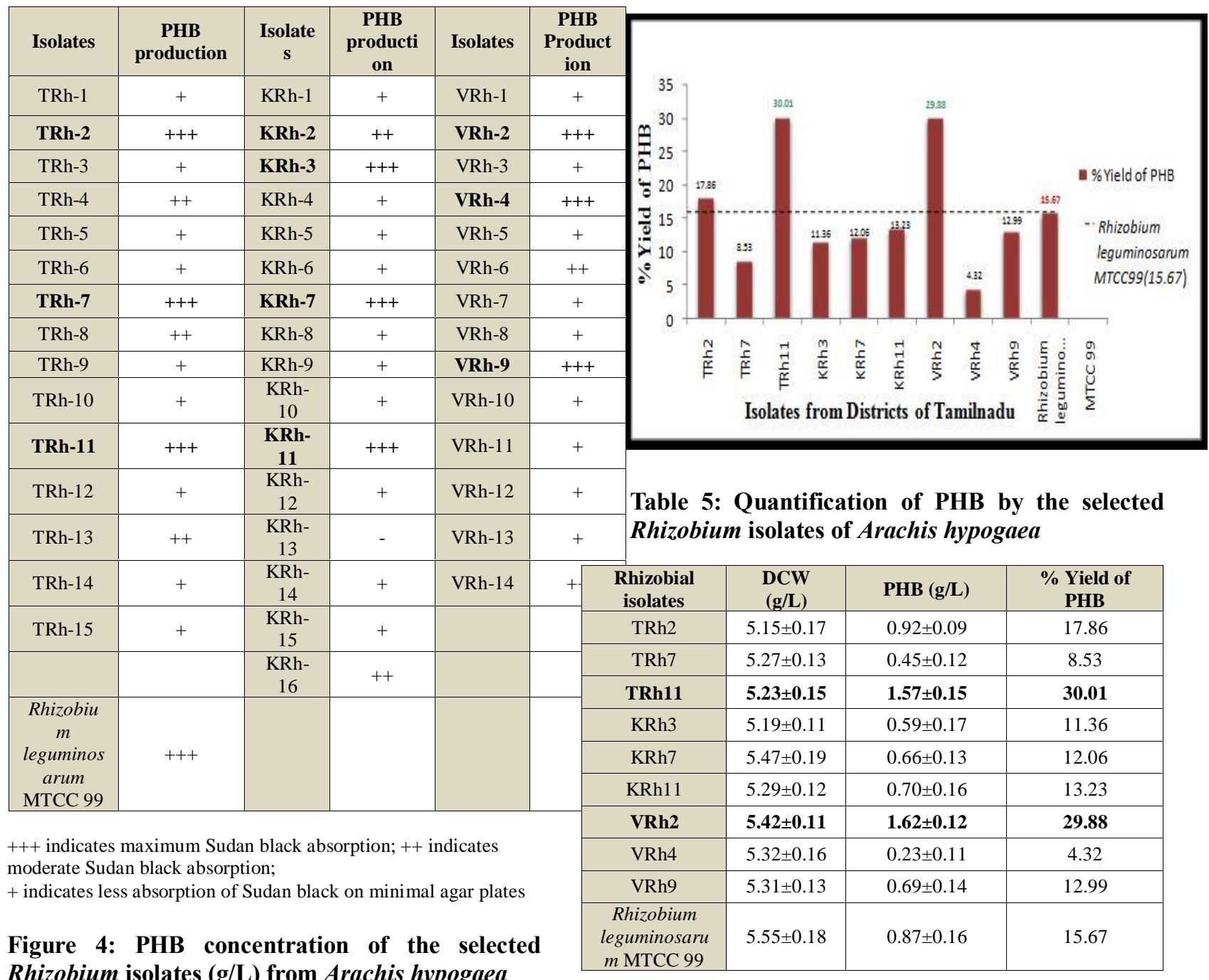

Rhizobium isolates (g/L) from Arachis hypogaea

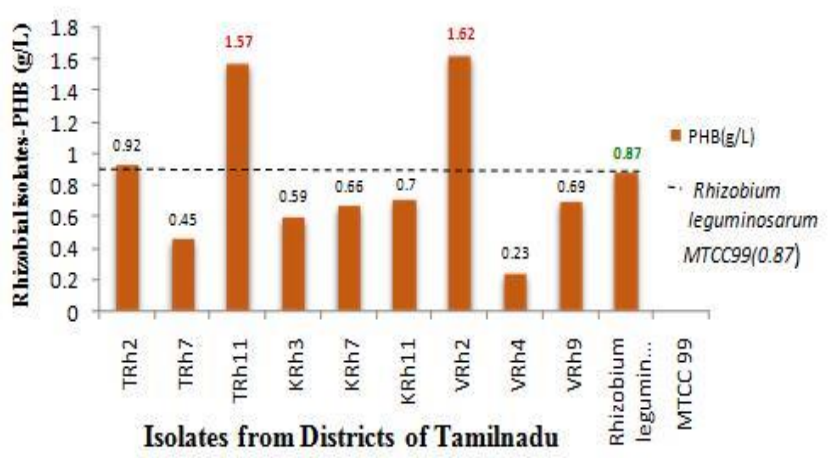

(Average of three values presented as Mean \pm SD)

3.8. Antagonistic activity of Rhizobium against fungal pathogens

In vitro antagonistic potential of the selected nine Rhizobium isolates (VRh9, KRh7, TRh11, VRh2, KRh11, TRh7, KRh3, VRh4 \& TRh2) along with MTCC reference strain were tested against Aspergillus niger and Fusarium oxysporum in dual culture under in vitro conditions and the percentage of inhibition was recorded. After five days of incubation, inhibition zone was clearly visible. All isolates were found to be inhibitory against fungal strains, yet, maximum inhibition potential was exhibited by two rhizobial isolates TRh11 and $\mathrm{VRh} 2$. Rhizobium TRh11 isolate recorded a growth inhibition percentage of $58 \%$ and 
59\% against Fusarium oxysporum and Aspergillus niger respectively. Rhizobium $\mathrm{VRh} 2$ isolate exhibited $58 \%$ and $63 \%$ growth inhibition against Fusarium oxysporum and Aspergillus niger respectively. The other isolates showed minimal growth inhibition when compared to TRh11 and VRh2. The percentage of growth inhibition of the selected fungal strains depicted in figures $6.1 \& 6.2$ infers that native Rhizobium isolates especially TRh11 and VRh2 could be considered for bio control activity.

Figure 6.1: Growth of inhibition (\%) of effective Rhizobium isolates against Fusarium oxysporum (Values are replicates of three values (Mean \pm SD))

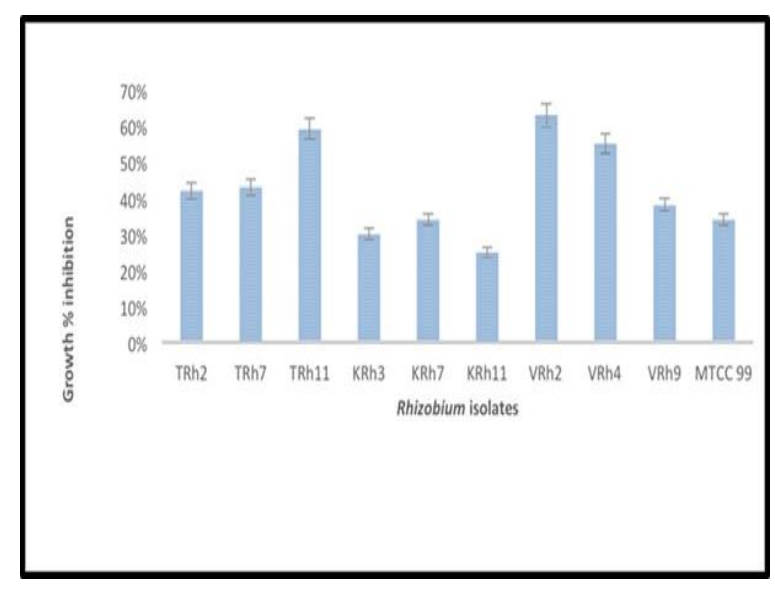

Figure 6.2: Growth of inhibition (\%) of effective Rhizobium isolates against Aspergillus niger (Values are replicates of three values (Mean $\pm \mathrm{SD}$ ))

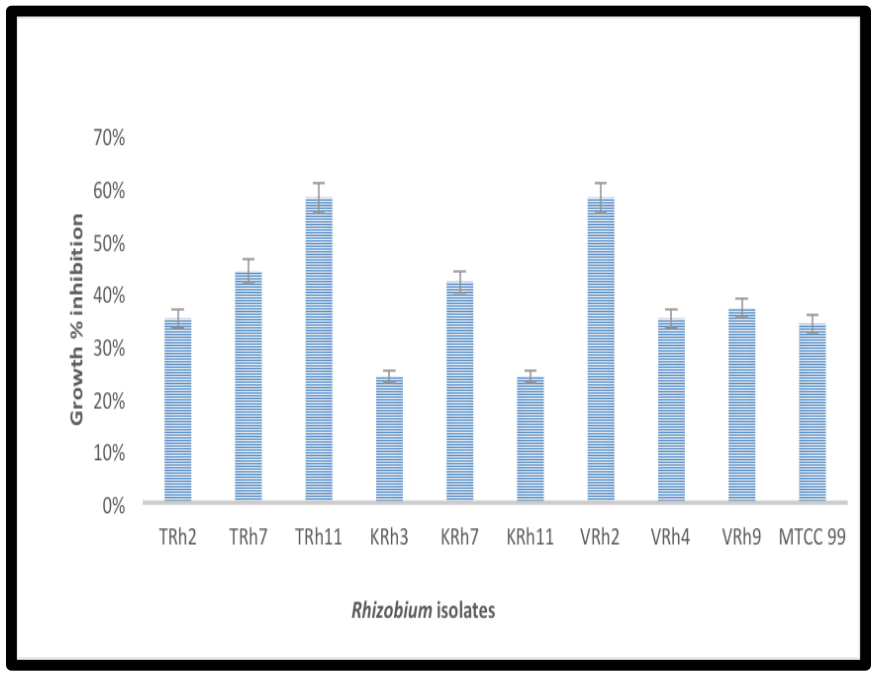

\section{DISCUSSION}

Mobilization of nutrients, production of IAA, EPS, HCN, Siderophore, ammonia with enhanced stress resistance and solubilization of phosphates are the primary mechanisms of plant growth promotion habituated by rhizobia.

Chemical substances occurring naturally, possessing indole nucleus are termed as Indole Acetic Acid (IAA). This phytohormone acting as a regulator of the physiological activities and growth in plants is widely produced by symbiotic bacteria ${ }^{22}$. In plants, lateral root initiation, cell enlargement and division are controlled by $\mathrm{IAA}^{23}$ and $74 \%$ of the rhizobacteria tested produced IAA ${ }^{24}$. In the present investigation of 45 isolates, nine isolates (VRh9, $\mathrm{KRh} 7, \mathrm{TRh} 11, \mathrm{VRh} 2$, KRh11, TRh7, KRh3, VRh4 \& TRh2) showed increased production of IAA when compared to the standard strain (Table 1). In the current study, varied IAA production levels by strains of Rhizobium is dependent on cultural conditions as reported by many workers. This enhanced IAA production capability not only helps in the establishment of effective symbiosis but also promotes the plant growth ${ }^{25}$. Screening for the production of IAA is an important strategy while developing bio-inoculants for promoting growth of plants $^{26}$.

Polysaccharide production is a marked characteristic of rhizobia and involved in infection process and nodule formation. Polysaccharides also protect rhizobia in the soil against deleterious biotic and abiotic stress factors and also restrict the oxygen diffusion through the nodular cells to protect the oxygen sensitive nitrogenase in the nodules ${ }^{27}$. Most of the rhizobial isolates secreted EPS in the current study. Among the 45 strains tested, the maximum EPS production was observed in nine isolates (VRh9, KRh7, TRh11, VRh2, KRh11, TRh7, KRh3, VRh4 \& $\mathrm{TRh} 2$ ). This finding implies that such strains when used as bio-inoculants could improve the symbiotic association and colonize the rhizosphere of groundnut effectively. Many experiments have shown that rhizobia secreting EPS are good colonizers $^{28}$ of legumes and non-leguminous plants ${ }^{29}$. Desiccation survival of rhizobia required an increased EPS production $^{30}$. Rhizobial adaptation ${ }^{31}$ to changing environmental conditions ${ }^{32}$ and for interaction with legumes to initiate ${ }^{33}$ and form infectious threads is dependent on EPS.

The present findings showed that 27 isolates of 45 strains tested were positive for Siderophore production which helps in iron acquisition and possess biocontrol ability. The maximum good growth recorded and expressed as "++", was observed in nine Rhizobium isolates compared to MTCC (Table 2). Few 


\section{International Journal of Engineering Applied Sciences and Technology, 2020 Vol. 5, Issue 6, ISSN No. 2455-2143, Pages 274-287 \\ Published Online October 2020 in IJEAST (http://www.ijeast.com)}

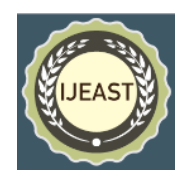

isolates tested negative for Siderophore production might use alternate chelating agents to facilitate iron transfer. Production of Hydrogen Cyanide and Siderophores are important attributes of PGPR that influence plant growth indirectly and strengthens the host disease mechanism. Bacterial siderophores have been demonstrated to have direct benefits to plant growth promotion by acting as a direct source of iron ${ }^{34}$ and making it available to plants ${ }^{35}$. Thus, cyanide and siderophores have an important role in the biocontrol activity against soil borne phytopathogens, beside the essential function of siderophores in the improvement of iron nutrition. $32 \mu \mathrm{g} / \mathrm{mL}$ of hydroxymate siderophores ${ }^{36}$ production by $M$. loti after 48 hours of incubation was observed which could be attributed to the growth inhibition of Sclerotinia sclerotiorum in dual culture technique. Production of Siderophore results in competition based exclusion of siderophore non-producer pathogens from the rhizosphere region due to lack of iron depletion required for hyphal growth and germination. A rhizosphere isolate Bacillus subtilis $\mathrm{BN}^{37}$ inhibited the growth of $M$. phaseolina up to $60 \%$.

Of all the tested Rhizobium isolates (45) for Hydrogen Cyanide, nine isolates showed excellent production and few isolates resulted in moderate production levels (Table 3). Presence or absence and intensity of Hydrogen Cyanide production can play a significant role in antagonistic potential of bacteria against phytopathogens. Production of Hydrogen Cyanide was an important trait in a PGPT in controlling fungal diseases in wheat seedlings under in vitro conditions ${ }^{38}$. The ability of Rhizobium and Bradyrhizobium strains to secrete hydrogen cyanide is a notable feature ${ }^{39}$.

The second most important biological process in the earth is nitrogen fixation which has assumed greater significance as it is the major source of fixed nitrogen. Biological nitrogen fixation (BNF) contribute to groundnut productivity both directly, or indirectly by improving sustainability or inducing soil fertility in the agricultural system by adding nitrogen to the soil and to the crops. Nitrogen fixation by rhizobia and its supply to the legumes through nodule formation is of great importance as it is concerned as one of the PGPR traits. In the present study, total nitrogen assay by Micro Kjeldahl method evaluated the levels of nitrogen fixed easily. It was found that VRh9, KRh7, TRh11, VRh2, KRh11, TRh7, KRh3, VRh4 \& TRh2 isolates along with MTCC showed a marked increase in nitrogen fixation. The research results show considerable variation in the percentage of nitrogen fixed by the isolated strains. Among the nine isolates which efficiently fixed more nitrogen, VRh2 and TRh11 fixed nitrogen at a percentage range of $0.52-0.53 \%$ equivocal to the MTCC standard (figures 2.1, $2.2 \& 2.3$ ). Literature supports that the symbiotic interactions between a legume and rhizobia resulting in a unique, nitrogen fixating plant organ, the nodule symbiotic nitrogen fixation in legumes is well known, which help to reduce the application of inorganic nitrogen and can also play a major role as green manure in improving the soil fertility ${ }^{40} \& 41$. In peanuts, the potential of enhancing nitrogen fixation at higher levels is associated with these symbiotic associations. Seventy million metric tons of fixed nitrogen per year accounting to $40 \%$ of the total $\mathrm{N}$ fixed on earth is contributed by Rhizobium - legume association $^{42}$. The potential of native rhizobia isolates in enhancing nitrogen fixation and bean production thereby adding value to agroecosystem has been proved $^{43}$.

Ammonia produced by the rhizobia can be taken up by the plants as a source of nitrogen for their growth. The ammonia production results of the test isolates showed varied outcome (Figure 3 ). $78 \%$ of the isolates were able to produce ammonia even though all the isolates fixed nitrogen at a specific concentration. This suggests that it is vital to select a nitrogen fixer with ammonia production in a biofertilizer consortia for agriculture practices.

Current scenario in the agricultural sector involving rhizobial biofertilizers over commercial chemical fertilizers reveals that rhizobial inoculants have notable qualities with addition to nitrogen fixing capacity with enhanced nodulation, such as production of plant growth promoting hormones like Indole acetic acid (IAA), secretion of siderophores and solubilization of phosphates etc. Exopolysaccharide (EPS) produced by Rhizobium is one such signal for host specificity during the early stage of root hair infection ${ }^{44}$. It also protects the cell from desiccation and predation and helps in nitrogen fixation by preventing high oxygen tension ${ }^{45}$. Nutman documented the positive influence of plant growth by indole acetic acid ${ }^{46}$. The production of EPS and IAA are considered as important traits of plant growth promoting rhizobacteria which indicates the achievement of active biological nitrogen fixation in the presence of rhizobial isolates which correlates with the findings in this research. Similar observations have also been reported in several plant species previously ${ }^{47}$ $\& 48$. These observations of the current work revealed the potentiality of isolated strains to increase nitrogen content through production of phytohormones may contribute to peanut growth promotion by suitable strains.

PHB synthesized by many species of rhizobacteria has shown to improve survivability during starvation. Furthermore, it helps the bacteria to 


\section{International Journal of Engineering Applied Sciences and Technology, 2020 \\ Vol. 5, Issue 6, ISSN No. 2455-2143, Pages 274-287 \\ Published Online October 2020 in IJEAST (http://www.ijeast.com)}

tolerate extreme high temperatures ${ }^{49}$, desiccation ${ }^{50}$, osmotic stress and hydrogen peroxide exposure ${ }^{51}$. Most efficient PHB producing bacteria belong to the genus Rhizobium $^{52}$. The polymer accumulation inside the cells is an attribute of nutrient imbalance and its synthesis is related to energy requirements of the cell. Qualitative screening for PHB production indicated that all the 45 isolates showed positive results, and the isolates VRh9, KRh7, TRh11, VRh2, KRh11, TRh7, KRh3, VRh4 \& TRh2 showed maximum absorption (Table 4). Based on the qualitative screening, nine isolates were subjected to quantitative method to estimate the yield of PHB. The findings suggest that TRh11 and VRh2 produced $30.11 \%$ and $29.88 \%$ respectively than the reference strain (Table 5). The competing effect of nodulation is affected due to disrupted PHB gene synthesis in rhizobia ${ }^{53} \& 54$. As rhizobial fitness is crucial during starvation, the capability to synthesize and degrade PHB by Rhizobium may improve by stabilizing cellular redox conditions.

To check the efficacy of antagonism of selected rhizobial isolates against soil borne fungal isolates (Aspergillus niger and Fusarium oxysporum) infecting groundnut plant, dual culture method was adapted and the percentage of inhibition of growth was recorded (Figures $6.1 \& 6.2$ ). As a result of the plate assay, some rhizobial isolates curtailed the growth of pathogenic fungi tested and were found to be highly inhibitory to Aspergillus niger and Fusarium oxysporum, whereas other strains showed only nominal antifungal activity. Rhizobial Strains VRh11 and TRh 2 suppressed the growth of tested fungi at higher percentage when compared to other strains tested. Similar results were observed by Antoun et al., 1998, who found that 49 of his rhizobial strains inhibited the growth of Fusarium oxysporum ${ }^{55}$. By inoculating the strains of antifungal ability, a significant reduction in Damping -off or Wilt disease of groundnut plant could be achieved thereby reducing the percentage of crop loss. Such biocontrol agents have also been reported to produce toxic metabolites, enzymes or volatile compounds which have inhibitory effects on soil-borne pathogens ${ }^{56}$. One of the mechanisms adapted by rhizobia to control fungal pathogens is production of siderophores, cell wall degrading enzymes and cyanogenic compounds. The strains which showed positive results for phosphate solubilization, cyanide production, siderophore production and produced cell wall degrading enzymes, gave the highest percentage of inhibition when tested for antagonistic activity and classified as the most effective isolates among the others in dual culture tests. The biocontrol ability of sixteen native isolates of Mesorhizobium strains in vitro against Fusarium species has been identified in previous studies ${ }^{57}$.

The ability of tested Rhizobium isolates to exhibit some PGP properties was evaluated under in vitro conditions in the present investigation. On the basis of the data obtained, it could be concluded that two of the Rhizobium isolates (VRh2 and TRh11) excelled in nitrogen-fixation performance, growth factor production studies, antagonistic activity and PHB production.

\section{CONCLUSION}

The current study paves the way for the ideal selection of Rhizobium possessing PGPR properties and proven antagonistic activity for their consistent performance on the growth and yield of groundnut under field conditions. Selection of the appropriate rhizobial inoculant improves nitrogen fixation and food production. Considering every perspective, the present study was mainly taken up to understand the impact of rhizobial bioinoculants isolated from the native lands of Tamil Nadu and to use it as a biofertilizer for stimulating the growth of groundnut crop. The ability of tested Rhizobium isolates exhibiting some PGP-properties, namely, IAA production, EPS, siderophores, ammonia, $\mathrm{HCN}$, nitrogen fixation and antagonistic activity evaluated under in vitro conditions proved the efficacy of strains which indicates that inoculation of native Rhizobium leguminosarum strain TRh11h exemplifies beneficiary response on groundnut.

\section{ACKNOWLEDGEMENT:}

The author acknowledges Dr. Kannan, Assistant Professor, Department of Zoology, VHNSN College, Tamil Nadu for his support and guidance.

\section{REFERENCES}

1. Vejan, P., Abdullah, R., Khadiran, T., Ismail, S., \& Nasrulhaq Boyce, A. (2016). Role of plant growth promoting rhizobacteria in agricultural sustainability - a review. Molecules, (pp. 573).

2. Manasa, K., S. R. Reddy, and S. Triveni. (2017). Characterization of potential PGPR and antagonistic activities of Rhizobium isolates from different rhizosphere soils. J Pharmacogn Phytochem, (pp. 51-54).

3. Arora, N. K., V. Kumar, and D. K. Maheshwari. (2001). "Constraints, development and future of the inoculants with special reference to rhizobial 


\section{International Journal of Engineering Applied Sciences and Technology, 2020 Vol. 5, Issue 6, ISSN No. 2455-2143, Pages 274-287 \\ Published Online October 2020 in IJEAST (http://www.ijeast.com)}

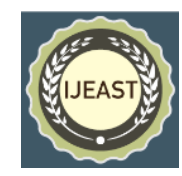

inoculants. Innovative approaches in microbiology. Singh and Singh, Dehradun, (pp. 241-245).

4. Mathur, N. K., and V. Mathur. (2001). Microbial polysaccharides: emerging new industrial products. Chem Week, (pp. 151-159).

5. Berraho, E. L., Didier Lesueur, Hoang Gia Diem, and Albert Sasson. (1997). Iron requirement and siderophore production in Rhizobium ciceri during growth on an iron-deficient medium. World Journal of Microbiology and Biotechnology, (pp.501-510).

6. Bai, Yuming, Alfred Souleimanov, and Donald L. Smith. (2002). An inducible activator produced by a Serratia proteamaculans strain and its soybean growthpromoting activity under greenhouse conditions. Journal of experimental botany, (pp. 1495-1502).

7. Bergersen, F. J., M. B. Peoples, and G. L. Turner. (1991). A role for poly- $\beta$-hydroxybutyrate in bacteroids of soybean root nodules. Proceedings of the Royal Society of London. Series B: Biological Sciences, (pp.59-64).

8. Tal, Sara, and Yaacov Okon. (1985). Production of the reserve material poly- $\beta$-hydroxybutyrate and its function in Azospirillum brasilense Cd. Canadian journal of microbiology 31, (pp. 608-613).

9. Bardin, Sylvie D., Hung-Chang Huang, Joanna Pinto, Eric J. Amundsen, and R. Scott Erickson. (2004). Biological control of Pythium damping-off of pea and sugar beet by Rhizobium leguminosarum bv. Viciae. Canadian journal of botany, (pp. 291-296).

10. Sarwar, M., and R. J. Kremer. (1995). Determination of bacterially derived auxins using a microplate method. Letters in applied microbiology, (pp. 282-285).

11. Damery, J. T., and M. Alexander. (1969). Physiological differences between effective and ineffective strains of Rhizobium. Soil Science, (pp.209-216).

12. Schwyn, Bernhard, and J. B. Neilands. (1987). Universal chemical assay for the detection and determination of siderophores. Analytical biochemistry, (pp.1 47-56).

13. Lorck, H. "Production of hydrocyanic acid by bacteria. (1948). Physiologia Plantarum, (pp. 142146.

14. Bremner, J. M., and A. P. Edwards. (1965). Determination and isotope-ratio analysis of different forms of nitrogen in soils: I. Apparatus and procedure for distillation and determination of ammonium 1." Soil Science Society of America Journal, (pp. 504507).

15. Okalebo, J. Robert, Kenneth W. Gathua, and Paul L. Woomer. (2002). Laboratory methods of soil and plant analysis: a working manual second edition. Sacred Africa, Nairobi 21.
16. Cappuccino, James G., and Natalie Sherman. Microbiology: a laboratory manual. San Francisco: Pearson/Benjamin Cummings (2005).

17. Williamson, D. H., and J. F. Wilkinson. (1958). The isolation and estimation of the poly- $\beta$-hydroxybutyrate inclusions of Bacillus species." Microbiology, (pp. 198-209).

18. Arnold, L., J. Demain, and E. Davis. (1999):

Polyhydroxyalkanoates. Manual of microbiology and biotechnology, (pp.616-627).

19. Bowker, R. R. (1981). Manual of methods for general bacteriology. American Society for Microbiology, Washington DC.

20. Du, Guocheng, Jian Chen, Jian Yu, and Shiyi Lun. (2001): Continuous production of poly-3hydroxybutyrate by Ralstonia eutropha in a two-stage culture system. Journal of biotechnology, (pp.1 5965).

21. Arfaoui, A., B. Sifi, A. Boudabous, I. El Hadrami, and M. Cherif. (2006). Identification of Rhizobium isolates possessing antagonistic activity against Fusarium oxysporum f. sp. ciceris, the causal agent of Fusarium wilt of chickpea. Journal of Plant Pathology (pp.67-75).

22. Zakharova, Elena A., Alexander A. Shcherbakov, Vitaly V. Brudnik, Nataliya G. Skripko, Nail Sh Bulkhin, and Vladimir V. Ignatov. (1999). Biosynthesis of indole-3-acetic acid in Azospirillum brasilense: Insights from quantum chemistry. European journal of biochemistry, (pp.572-576).

23. Glick, Bernard R. (2012). Plant growth-promoting bacteria: mechanisms and applications. Scientifica 2012.

24. Halda-Alija, Lidija. (2003). Identification of indole-3-acetic acid producing freshwater wetland rhizosphere bacteria associated with Juncus effusus L. Canadian journal of microbiology, (pp.781-787). 25. Vasconcellos, Rafael Leandro Figueiredo de, Mylenne Calciolari Pinheiro da Silva, Carlos Marcelo Ribeiro, and Elke Jurandy Bran Nogueira Cardoso. (2010). Isolation and screening for plant growthpromoting (PGP) actinobacteria from Araucaria angustifolia rhizosphere soil. Scientia Agricola, (pp.743-746).

26. Hassen, Ahmed Idris, F. L. Bopape, and L. K. Sanger. (2016). Microbial inoculants as agents of growth promotion and abiotic stress tolerance in plants. In Microbial inoculants in sustainable agricultural productivity, Springer, New Delhi,

(pp. 23-36).

27. Sayyed, R. Z., D. D. Jamadar, and P. R. Patel. (2011): Production of Exo-polysaccharide by Rhizobium Sp. Indian journal of microbiology, (pp.294-300). 


\section{International Journal of Engineering Applied Sciences and Technology, 2020 Vol. 5, Issue 6, ISSN No. 2455-2143, Pages 274-287 \\ Published Online October 2020 in IJEAST (http://www.ijeast.com)}

28. Chabot, Rock, Hani Antoun, and Michel P. Cescas. (1996): Growth promotion of maize and lettuce by phosphate-solubilizing Rhizobium leguminosarum biovar. phaseoli." Plant and soil, (pp.311-321).

29. Bianciotto, V., S. Andreotti, R. Balestrini, P. Bonfante, and S. Perotto. (2001). Extracellular polysaccharides are involved in the attachment of Azospirillum brasilense and Rhizobium leguminosarum to arbuscular mycorrhizal structures. European journal of histochemistry, (pp. 39-50).

30. Hartel, Peter G., and Martin Alexander. (1986). Role of extracellular polysaccharide production and clays in the desiccation tolerance of cowpea Bradyrhizobia. Soil Science Society of America Journal, (pp. 1193-1198).

31. Skorupska, Anna, Monika Janczarek, Małgorzata Marczak, Andrzej Mazur, and Jarosław Król. (2006). Rhizobial exopolysaccharides: genetic control and symbiotic functions. Microbial cell factories, (pp.7).

32. Ivashina, Tanya V., and Vladimir N. Ksenzenko. (2012). Exopolysaccharide biosynthesis in Rhizobium leguminosarum: from genes to functions. The complex world of polysaccharides (pp.99-127).

33. Ghosh, Pallab Kumar, and Tushar Kanti Maiti. (2016). Structure of extracellular polysaccharides (EPS) produced by rhizobia and their functions in legume-bacteria symbiosis: a review. Achievements in the Life Sciences, (pp. 136-143).

34. Yehuda, Zehava, Moshe Shenker, Volker Romheld, Horst Marschner, Yitzhak Hadar, and Yona Chen. (1996). The role of ligand exchange in the uptake of iron from microbial siderophores by gramineous plants. Plant Physiology, (pp. 12731280).

35. Vansuyt, Gérard, Agnès Robin, Jean-François Briat, Catherine Curie, and Philippe Lemanceau. (2007). Iron acquisition from Fe-pyoverdine by Arabidopsis thaliana. Molecular Plant-Microbe Interactions, (pp. 441-447).

36. Chandra, Shikha, Kamlesh Choure, Ramesh C. Dubey, and Dinesh K. Maheshwari. (2007). Rhizosphere competent Mesorhizobium loti MP6 induces root hair curling, inhibits Sclerotinia sclerotiorum and enhances growth of Indian mustard (Brassica campestris). Brazilian Journal of Microbiology, (pp. 124-130).

37. Singh, Neetu, Piyush Pandey, R. C. Dubey, and D. K. Maheshwari. (2008). Biological control of root rot fungus Macrophomina phaseolina and growth enhancement of Pinus roxburghii (Sarg.) by rhizosphere competent Bacillus subtilis BN1. World Journal of Microbiology and Biotechnology, (pp.1669).
38. Cattelan, A. J., P. G. Hartel, and J. J. Fuhrmann. Screening for plant growth-promoting rhizobacteria to promote early soybean growth. (1999). Soil Science Society of America Journal, (pp.1670-1680).

39. Antoun, Hani, Chantal J. Beauchamp, Nadia Goussard, Rock Chabot, and Roger Lalande. (1998). Potential of Rhizobium and Bradyrhizobium species as plant growth promoting rhizobacteria on nonlegumes: effect on radishes (Raphanus sativus L.). In Molecular microbial ecology of the soil, Springer, Dordrecht, (pp. 57-67).

40. Sanginga, N., J. A. Okogun, I. O. Akobundu, and B. T. Kang. (1996). Phosphorus requirement and nodulation of herbaceous and shrub legumes in low $\mathrm{P}$ soils of a Guinean savanna in Nigeria. Applied Soil Ecology, (pp.247-255).

41. Bellone, C. H., S. D. V. C. De Bellone, R. O. Pedraza, and M. A. Monzon. (1997). Cell colonization and infection thread formation in sugar cane roots by Acetobacter diazotrophicus. Soil Biology and Biochemistry, (pp. 965-967).

42. McInnes, Alison, and Krystina Haq. (2007). Contributions of rhizobia to soil nitrogen fertility." In Soil Biological Fertility, Springer, Dordrecht, (pp. 99-128).

43. Koskey, Gilbert, Simon W. Mburu, Ezekiel M. Njeru, Jacinta M. Kimiti, Omwoyo Ombori, and John M. Maingi. (2017). Potential of native rhizobia in enhancing nitrogen fixation and yields of climbing beans (Phaseolus vulgaris L.) in contrasting environments of Eastern Kenya. Frontiers in plant science, (pp. 443).

44. Olivares, J., M. A. Herrera, and E. J. Bedmar. (1988). Woody legumes in arid and semi-arid zones: The Rhizobium-Prosopis chilensis symbiosis. In Nitrogen Fixation by Legumes in Mediterranean Agriculture, Springer, Dordrecht, (pp. 65-72).

45. Jarman, T. R., L. Deavin, S. Slocombe, and R. C. Righelato. (1978). Investigation of the effect of environmental conditions on the rate of exopolysaccharide synthesis in Azotobacter vinelandii. Microbiology, (pp.59-64).

46. Nutman, P. S. (1977). Study frameworks for symbiotic nitrogen fixation. In Recent Developments in Nitrogen Fixation; an International Symposium.

47. Majeed, Afshan, M. Kaleem Abbasi, Sohail Hameed, Asma Imran, and Nasir Rahim. (2015). Isolation and characterization of plant growthpromoting rhizobacteria from wheat rhizosphere and their effect on plant growth promotion." Frontiers in microbiology, (pp. 198).

48. Pankievicz, Vânia CS, Fernanda P. do Amaral, Karina FDN Santos, Beverly Agtuca, Youwen Xu, Michael J. Schueller, Ana Carolina M. Arisi et al. (2015). Robust biological nitrogen fixation in a model 
grass-bacterial association. The Plant Journal, (pp. 907-919).

49. Kadouri, Daniel, Edouard Jurkevitch, and Yaacov Okon. (2003). Involvement of the reserve material poly- $\beta$-hydroxybutyrate in Azospirillum brasilense stress endurance and root colonization." Appl. Environ. Microbiol., (pp.3244-3250).

50. Tavernier, Patricia, J. Portais, Sa Nava, J. O. S. I. A. N. E. Courtois, B. E. R. N. A. R. D. Courtois, and J. Barbotin. (1997). Exopolysaccharide and Poly(beta)-Hydroxybutyrate Coproduction in Two Rhizobium meliloti Strains. Appl. Environ. Microbiol., (pp. 21-26).

51. Tamdoğan, Nazan, and Uğur Sidal. (2011). Investigation of poly- $\beta$-Hydroxybutyrate (PHB) production by Bacillus subtilis ATCC 6633 under different conditions. Kafkas Univ Vet Fak Derg., (pp.173-176).

52. Aslim, Belma, Z. N. Yuksekdag, and Yavuz Beyatli. (2002). Determination of PHB growth quantities of certain Bacillus species isolated from soil. Turkish Electronic Journal of Biotechnology, (pp.24-30).

53. Willis, Laura B., and Graham C. Walker. (1998). The phbC (poly- $\beta$-hydroxybutyrate synthase) gene of Rhizobium (Sinorhizobium) meliloti and characterization of phbC mutants. Canadian journal of microbiology, (pp.554-564).

54. Aneja, P., A. Zachertowska, and T. C. Charles. (2005). Comparison of the symbiotic and competition phenotypes of Sinorhizobium meliloti PHB synthesis and degradation pathway mutants. Canadian journal of microbiology, (pp.599-604).

55. Antoun, Hani, Chantal J. Beauchamp, Nadia Goussard, Rock Chabot, and Roger Lalande. (1998). Potential of Rhizobium and Bradyrhizobium species as plant growth promoting rhizobacteria on non-legumes: effect on radishes (Raphanus sativus L.). In Molecular microbial ecology of the soil, Springer, Dordrecht, (pp. 57-67).

56. Yaqub, Fouzia, and S. A. L. E. E. M. Shahzad. (2011). Efficacy and persistence of micobial antagonists against Sclerotium rolfsii under field conditions. Pakistan Journal of Botany, (pp.26272634).

57. Bhagat, Divya, Poonam Sharma, Asmita Sirari, and K. C. Kumawat. (2014). Screening of Mesorhizobium spp. for control of Fusarium wilt in chickpea in vitro conditions. Int J Curr Microbiol Appl Sci., (pp.923-930). 